\title{
Knowledge, attitudes and practices on child feeding among child care providers of preschools in a nutritionally vulnerable district in Sri Lanka
}

\author{
H.G. Jayakody ${ }^{1 *}$, D.E. Attygalle ${ }^{2}$
}

\begin{abstract}
Background

Role of child care providers in changing eating habits and food consumption among preschool children is often highlighted.
\end{abstract}

\section{Objectives}

This study described knowledge, attitudes and practices on child feeding and factors associated with knowledge and attitudes among child care providers of preschools in Nuwaraeliya district, .

\section{Methods}

Cross sectional descriptive study was conducted in three divisional secretariat areas in Nuwaraeliya district in a sample of 427 preschool teachers who are working in child care centres for more than 1 year.

\section{Results}

Response rate for the self-administered questionnaire was $82.1 \%(n=344)$. Mean total knowledge score was 5.49 (SD 1.9) and $52.6 \%(\mathrm{n}=181)$ scored more than $50 \%$ of the total score. Positive attitudes toward child feeding were reported as $63.7 \%(n=219)$. Statistically significant associations for both knowledge score and attitude level were observed with ethnicity $(\mathrm{p}=0.001)$, level of education ( $p=0.001)$, minimal duration of basic training $(p=0.008$ and $p=0.001)$, type of in-service nutrition training programme attended $(\mathrm{p}=0.0001$ and $\mathrm{p}=0.009)$ and the sector of employment of the child care provider $(\mathrm{p}=0.0001$ and $\mathrm{p}=0.003$ ). Participation of care providers during feeding of children was $83.3 \%(n=283)$. Almost $59 \%(n=223)$ incorporated nutrition messages into routine teaching.

\section{Conclusion}

Standard basic training and well organized in-service training are some of the modifiable factors in improving the knowledge and attitudes on child feeding among preschool teachers..

Key words: Preschool nutrition, child care providers, child feeding

\section{Introduction}

Transition from a preschool to the formal education is a critical point in a life of a small child. One of the aims of preschool education is to develop a child who enters the formal school with social adaptability, taking meals together, with appropriate health and nutrition habits along with many social capabilities (1). Knowing the role played by child care providers and child care centers in a life of undernourished child,

1. Post Graduate Trainee in Community Medicine, Ministry of Health, Nutrition and Indigenous Medicine, Colombo, Sri Lanka

2. Consultant Community Physician and Health Specialist, UNICEF Sri Lanka

*Correspondence: gayathri_hj@yahoo.com

DOI: $10.4038 /$ jccpsl.v21i1.8074 
multiple interventions are conducted targeting these centers. However implementation of these activities is governed by the knowledge and attitudes of child care providers on child nutrition.

Knowledge on child nutrition influences child care providers' nutritional practices at the child care setting $(2,3)$. These practices make an impact on preschoolers' nutritional status in short and long term (4).

District of Nuwaraeliya in Sri Lanka has one of lowest preschool age nutritional indicators in the country and that remain stagnant of the years $(5$, 6). Prevalence of underweight in 2-5 years age group was $36.9 \%$ and moderate stunting among children in the same age group was $40.9 \%$ in 2009 in Nuwaraeliya. Several micronutrient deficiencies were also observed in the same age group in recent studies (7).

Majority of children in this age group in Nuwaraeliya district attends to center based child care programmes regularly. Currently there are feeding programmes implemented for this target group such as supplementary feeding programmes, midday meal programmes and provision of glass of milk. Neither their coverage nor their effectiveness was assessed in the local setting. However, effective utilization of resources and manpower available in the child care setting paves path to effective interventions to alleviate under nutrition among preschool children.

Expected outcome of the study is to identify factors which will associate with knowledge and attitudes of child care providers on child feeding and to describe few feeding practices in the centers. This information will be useful in designing targeted nutritional interventions for child care centers. The aim of this study is to assess the knowledge and attitudes among child care providers on child feeding and their associated factors and to describe key selected feeding practices in child care setting.

\section{Methods}

A cross sectional analytical study was conducted to achieve the above objectives. Nuwaraeliya district has 5 local authorities, of which 3 were randomly selected to the study. Study population consisted of preschool teachers who were working in child care centres in selected local authority areas for minimum of 1 year. There was no exclusion criterion.

Sampling frame for the study was a list of registered child care centres obtained from the local authority. Comprehensive list of child care providers in centers in the area was not available, thus list of child care centers was used to select the study sample. From each centre, teacher in charge or chief child development officer was invited to participate in the study as they had same credentials and job functions at a child care center.

To obtain the maximum sample size, estimated proportion of care providers with good knowledge was considered as $50 \%$ and the expected precision was 0.05 . Total sample size for the study was 427 child care providers with an expected non response rate of $10 \%(8)$.

Multi stage sampling technique was adapted for the study. In the first stage 3 local authority areas were selected randomly. To calculate the number of child care centers from each area, population probability to size technique was applied to 427 child care centers. In the second stage, using the sampling frame, the required number of child care centres selected based on simple random sampling technique using table of random numbers. Then, from each child care center a single child care provider is invited for the study.

\section{Data collection instruments}

Pre tested self-administered questionnaire was used to collect data. There were 4 broad components in the questionnaire namely basic 
socio demographic variables, knowledge, attitudes and selected key practices variables.

Socio demographic variables served to describe the study population and to detect main correlates for knowledge and attitudes. They were described in 3 sections namely personal characteristics of the child care provider, variables to related to training of child care providers and variables related to child care centers.

Knowledge component of the questionnaire had 7 items namely essential nutrients contained in common food groups, food frequency, feeding techniques and improving the quality of the meal and was based on infant and young child feeding guideline issued by Ministry of Health in Sri Lanka in 2007 (9).

Attitude component was studied using 5-point Likert scale on 6 selected variables, namely perceived responsibility of child care providers, concern about child growth, forceful feeding, and restrictions to food access, monitoring the food intake and on food selection at the preschool setting. They were based on the seven factors of the child feeding questionnaire as presented by Birch et al., in 2001 (10).

Self reported practice was studied using a mixed method questionnaire which was developed based on the available literature and key informant interviews with experienced preschool teachers (11). Key variables studied under this section were in cooperation of nutritional concepts to early childhood education, communication with parents, quality of the meal in the child care center and meal time behaviour of the child care providers. Percent agreement calculated for selected variables by comparing self-reported practices with observations were more than $90 \%$.

The questionnaire was validated by a panel of experts on the fields of public health and early childhood education using modified Delphi technique. Questionnaire was translated to Sinhala and Tamil by two independent translators and back translated to ensure the originality. Cognitive interviews were held with five preschool teachers to assess the level of perception of the items. Finally questionnaire was pretested in 20 preschool teachers from the adjacent district before administering it to the study sample.

Data collection was done by specially trained data collectors delivering the questionnaire at selected child care centers. Informed written consent was obtained from those who were willing to participate in the study.

The study was conducted from August 2013 to January 2014.

\section{Data analysis}

Knowledge component in the questionnaire was analyzed as individual items and summarized to a knowledge score by allocating marks to those items. Attitudes were described in the 5-point Likert scale, with options varying from strongly disagree to strongly agree. Each response was assigned a rank ranging from -2 to +2 . Total for items calculated by adding them together. Key practices were described using proportions.

Bivariate analysis was conducted to assess the associations were good knowledge and attitudes scores, by categorizing them based on the score for each component. Significance testing and 95\% confidence interval were calculated for odds ratios. The study was reviewed by Ethical Review committee of Faculty of Medical sciences at University of Kelaniya.

\section{Results}

\section{Basic demographic information}

Response rate for the self-administered questionnaire was $82.1 \%(n=344)$. Thus, the study was participated by 193 child care providers who were employed at rural sector preschools and 151 care providers who were employed 
Table 1: Distribution of the study population by selected socio demographic variables $(n=344)$

Sector of the child care centers

Estate sector

Rural sector

Ethnicity

Sinhalese

Tamil and Muslim

Level of education of child care providers

Only primary education

Studied up to Ordinary level

Passed GCE ordinary level

Studied up to Advanced level

Passed Advanced level and above

151

193

154

1

36

121

66

116

172

44

Own children of the child care providers
Not responded

No children

Having children
$43.9 \%$

$56.1 \%$
$0.3 \%$

$10.4 \%$

$35.1 \%$

$19.1 \%$

$33.7 \%$

Type of basic training based on length of training

Received one year training $\quad 176$

Trained for less than 1 year

Not trained on preschool education

Not responded 
in estate sector. Participants of Sinhalese and Tamil ethnicities worked in centers belonging to both sectors. Distribution of socio demographic variables among the participants was described in table 1. Mean age of the participants was 37.6 years $(\mathrm{SD}=11.2)$. In a single child care centre, there was a mode of 1 teacher and one trained assistants. Mean number of children per centre was 31 .

\section{Knowledge}

Ability to recognize protein containing food groups by the child care providers was lower than the other food groups. For fish, meat and egg only $58.7 \%, 60.4 \%$ and $60.4 \%$ of child care providers responded correctly for the main type of food group they belong to. Responsive feeding as the ideal method to feed preschoolers was selected only by $52.3 \%(\mathrm{n}=180)$ of care providers. The definition of a "quality meal" was known by $88.8 \%(n=306)$ of the responders. Importance of hand washing prior to any meal was correctly identified by $86.3 \%(n=297)$. Only $18.5 \%$ of participants correctly understood the meaning of the term " wasting" and only $36 \%$ of them were able to interpret the WHO growth chart correctly.

Mean knowledge score among the study group was 5.49 (From the total score). In the knowledge score categorization, $52.6 \%(\mathrm{n}=181)$ had a satisfactory knowledge score while $47.4 \%$ had a low knowledge score.

\section{Attitudes}

Table 2 shows the responses for the attitude stems in the questionnaire. In the study, 219 child care providers exhibited good attitudes (proportion 63.7\%; 95\%CI 58.4-67.6) and 36.3\% scored poorly for the attitudes component.

\section{Associated factors}

Good knowledge on child feeding was positively associated with ethnicity $(\mathrm{p}=0.001)$, level of education of the child care provider $(\mathrm{p}=0.001)$, having children to the child care provider $(\mathrm{p}=0.029)$, reception of basic training of recommended duration $(p=0.008)$ and the employed sector of the child care provider $(\mathrm{p}=0.0001)$.

Attitudes on child feeding was positively associated with ethnicity $(p=0.001)$, reception of minimal recommended level of education for child care provider $(\mathrm{p}=0.001)$, reception of basic training of recommended duration $(p=0.001)$ number of teachers in the child care center for 20 children $(\mathrm{p}=0.0001)$ and with the employed sector of the child care provider $(\mathrm{p}=0.003)$.

\section{Practices on child feeding}

Majority of child care providers of the main sample reported that they participate in the meal with children $(83 \%, \mathrm{n}=283)$.

Majority ( $\mathrm{n}=744 ; 70.9 \%$ ) paid special attention to difficult eaters and underweight children during the meal time while only 25 (7.3\%) reported that they do not actively involved in the process (observe from a distance). Eight child care providers reported that they sit with children and teach them on table manners. Two hundred and three teachers $(59.0 \%)$ reported that they teach nutritional concepts to their children frequently.

Communication practices were assessed at two occasions namely daily interactions (at drop-ins or pickup of the child) and at parents meetings which are held at the centre in regular intervals. Hundred and ninety seven $(57.1 \%)$ claimed that they discuss and provide a feedback on children's food intake to parents daily. "Nutrition" was a common topic in parents' meetings in 326 child care centres $(94.7 \%)$. Common themes of discussion were child's growth, nutritious food preparation and parent participation in nutrition related activities in the preschool with a reported frequency of $62.4 \%, 52.2 \%$ and $54.7 \%$ respectively. 
Table 2: Distribution of child care providers by their attitudes on feeding practices ${ }^{\mathrm{a}} \quad(\mathrm{n}=344)$

\begin{tabular}{lrrrrrr}
\hline \multicolumn{1}{c}{ Variables } & $\begin{array}{c}\text { Strongly } \\
\text { agree }\end{array}$ & Agree & Neutral & $\begin{array}{r}\text { Disagree } \\
\text { Strongly } \\
\text { disagree }\end{array}$ & $\begin{array}{c}\text { Non } \\
\text { respond- } \\
\text { ents }\end{array}$ \\
\hline $\begin{array}{l}\text { Food intake of children during preschool } \\
\text { hours is a responsibility of preschool }\end{array}$ & 217 & 105 & 07 & 02 & 0 & 13 \\
teacher & $(63.1)$ & $(30.5)$ & $(2.0)$ & $(0.6)$ & $(0.0)$ & $(3.8)$ \\
$\begin{array}{l}\text { I believe that, child's growth is affected by } \\
\text { poor nutrition }\end{array}$ & 164 & 99 & 16 & 26 & 9 & 28 \\
We should force children to eat in order to & $(47.7)$ & $(28.8)$ & $(4.6)$ & $(7.6)$ & $(2.6)$ & $(8.1)$ \\
finish their meals & 78 & 126 & 27 & 63 & 26 & 24 \\
& $(22.7)$ & $(36.6)$ & $(7.8)$ & $(18.3)$ & $(7.5)$ & $(7.0)$ \\
We should make restrictions to access & 69 & 116 & 21 & 77 & 22 & 36 \\
certain types of food for children. & $(20.0)$ & $(33.7)$ & $(6.1)$ & $(22.4)$ & $(6.4)$ & $(10.0)$ \\
We should monitor daily food intake of & 187 & 123 & 05 & 05 & 6 & 18 \\
children during their child care centre stay & $(54.4)$ & $(35.7)$ & $(1.5)$ & $(1.5)$ & $(1.8)$ & $(5.2)$ \\
We should decide on children's meals & 183 & 97 & 29 & 15 & 2 & 18 \\
based on food diversification & $(53.2)$ & $(28.2)$ & $(8.4)$ & $(4.4)$ & $(0.6)$ & $(5.2)$ \\
\hline
\end{tabular}

a. number (\%) are given in each cell

Table 3: Association between selected socio demographic factors with knowledge and attitude variables

\begin{tabular}{|c|c|c|c|c|}
\hline \multirow[b]{2}{*}{ Variable } & \multicolumn{2}{|c|}{ Knowledge variable } & \multicolumn{2}{|c|}{ Attitude variable } \\
\hline & $\begin{array}{c}\text { OR } \\
\text { (Unadjusted ) }\end{array}$ & $\begin{array}{l}\text { Significance } \\
\text { level }\end{array}$ & $\begin{array}{l}\text { OR Sig } \\
\text { (Unadjusted) }\end{array}$ & $\begin{array}{l}\text { gnificance } \\
\text { level }\end{array}$ \\
\hline Sector of employment & $2.54(1.6-3.9)$ & $\mathrm{p}=0.001$ & $2.0(1.29-3.1)$ & $\mathrm{p}=0.003$ \\
\hline Child care provider being married & $1.02(0.63-1.67)$ & $\mathrm{p}=0.92$ & $0.8(0.47-1.4)$ & $\mathrm{p}=0.53$ \\
\hline Ethnicity & $5.24(3.3-8.3)$ & $\mathrm{p}=0.0001$ & $2.1(1.3-3.4)$ & $\mathrm{p}=0.001$ \\
\hline $\begin{array}{l}\text { Highest level of education } \\
\text { ( } \geq \text { advanced level) }\end{array}$ & $1.99(1.25-3.1)$ & $\mathrm{p}=0.02$ & $1.8(1.1-3.01)$ & $\mathrm{p}=0.001$ \\
\hline $\begin{array}{l}\text { Child care provider having own } \\
\text { children }\end{array}$ & $1.95(1.22-3.14)$ & $\mathrm{p}=0.03$ & $1.28(0.79-2.07)$ & $\mathrm{p}=0.304$ \\
\hline $\begin{array}{l}\text { Own child of the care provider in } \\
\text { the same centre }\end{array}$ & $1.22(0.67-2.22)$ & $\mathrm{p}=0.4$ & $1.73(0.9-3.3)$ & $\mathrm{p}=0.11$ \\
\hline $\begin{array}{l}\text { Length of basic training being } \\
\text { year }\end{array}$ & $4.1(2.14-3.9)$ & $\mathrm{p}=0.001$ & $2.8(1.46-5.4)$ & $\mathrm{p}=0.0011$ \\
\hline $\begin{array}{l}\text { Reception of in service training on } \\
\text { Child nutrition }\end{array}$ & $1.1(0.7-1.69)$ & $\mathrm{p}=0.77$ & $1.03(0.65-1.63)$ & $\mathrm{p}=0.569$ \\
\hline $\begin{array}{l}\text { Children to teacher ratio in the } \\
\text { wChild care centre }\end{array}$ & $1.45(0.9-2.32)$ & $\mathrm{p}=0.92$ & $1.9(1.17-3.07)$ & $\mathrm{p}=0.009$ \\
\hline
\end{tabular}




\section{Discussion}

Undernutrition has remained as one of the main health problems in Sri Lanka in spite of achieving the high indices in other health and development indices. Regional disparities in undernutrition further aggravates the problem (12). Ministry of Health addresses the importance of nutrition among preschool children in its National nutrition policy in 2010 .

Quality of early child care at a preschool is determined by efficient staff training and continuous professional development (14). From the total sample (344), 66.2\% reported that they have attended to an in-service training on child nutrition during past 3 years. Similar pattern was observed in other studies with $48 \%$ of child care providers who had exposure to in service training on child nutrition (11). Having the prevalence of undernutrition in the present study area may have influence in receiving the high coverage of training for service providers in the local setting.

Knowledge on child feeding concepts was satisfactory among the study participants with a mean knowledge score of 5.49 and $52.6 \%$ scoring a "good" knowledge level and 47.4\% scoring a poor knowledge level. Responsive feeding practices among care givers, improve eating behaviours and growth of young children (15). In the present study, $52.3 \%$ of child care providers had correct knowledge on the practice of responsive feeding, while $64 \%$ of child care providers had agreed that forceful feeding is necessary to finish their meals in time.

Further many studies have found that child care providers' feeding behaviours during the meal time has an impact on children's food consumption (3) and on development of eating habits of children (4). It is encouraging to note that, $83 \%$ teachers participated in the meal session with children. Majority (70.7\%) helped the children during the meal time while $23.9 \%$ and $18.4 \%$ of them appreciate and support individual child during meal and encourage them to enjoy new types of food respectively.

Preschool children are not too young to learn and to develop healthy food habits. Their categorization and perceptions are different from abstract thinking patterns of adults. But they develop opinions and concepts of food, based on experiences (4). In that context, child care center is based at a good platform to introduce these concepts through their activities. Utilization of this opportunity in the study sample was satisfactory, with $61.1 \%$ of child care providers claiming that they frequently teach nutritional concepts to their children. In observations, $38.9 \%$ of observed centres had picture displays on healthy foods such as fruits, vegetables and common food groups.

Effective communication with parents remains the main stay in quality child care provision (14). Opportunities in formal and informal communication environment should be utilized to create a discussion with parents on child feeding and their nutrition(16). In the present study, $62.1 \%$ of child care providers reported that they discuss and provide a feed back to parents on daily food intake of children. Further $26.5 \%$ provided a limited feedback to parents. At formal meetings with parents it was reported that "child nutrition" was a common topic (94.7\%). Chika et al, in 2011 in USA, conducted a study on attitudes and actions of staff related to communicating with parents about young child's eating and weight. In their study group, $52 \%$ reported that they have never discussed child weight related issues with parents (11). Difference for this practice and attitude in the two setting would be socio cultural values in Sri Lanka are different in the context of respect to teachers and concepts of shared responsibility of child health by various categories. Also American study has an assortment of staff categories in its scope, limiting the opportunities for participants to act in the desired behavior. But the present 
study included only child care providers so they were in direct contact with both children and parents.

Participants' responses for the self-administered questionnaire depend on their ability to understand and comprehend questions. It required recall of nutrition practices at child care centers retrospectively which can contribute to recall bias. In the inquiry of practices or attitudes, participants tend to report practices and attitudes which were not in practice, but tempted to answer positively. This may have resulted in social desirability bias. The study was conducted only in three divisional secretariat areas in Nuwaraeliya district. It included only registered child care centers in the division and the accuracy of the sampling frame was inconclusive. Non respondents to the questionnaire were not analyzed. They may be different from those who participated in the study.

\section{Recommendations}

Most of the factors associated with positive knowledge and attitudes are modifiable. Implementation of standard educational guidelines for preschool teachers and conduct of special programmes to improve knowledge on child feeding will help to improve the situation. Further studies are necessary to assess the outcome of training on the improvement of nutritional practices and behaviours on centers and preschool children respectively.

\section{Acknowledgement}

Ethical approval for the study was obtained from Ethics review committee, Faculty of Medicine, University of Kelaniya. For the guidance provided Board of Study in Community Medicine, Post Graduate Institute of Medicine, University of Colombo.

\section{Conflict of interests}

None declared

\section{References}

1. Ministry ofHuman Resource Development Education \& Cultural affairs. Education for all; National action plan. Colombo, Sri Lanka: Government of Sri Lanka; 2004.

2. Lanigan JD. The relationship between practices and child care providers' beliefs related to child feeding and obesity prevention. Journal of nutrition education and behavior. 2012;44(6):521-9.

3. Hughes SO, Patrick H, Power TG, Fisher JO, Anderson CB, Nicklas TA. The impact of child care providers' feeding on children's food consumption. Journal of developmental and behavioral pediatrics: JDBP. 2007;28(2):100-7.

4. Fuller C, Keller L, Olson J, Plymale A. Helping preschoolers become healthy eaters. Journal of pediatric health care. 2005;19(3):178-82.

5. Ministry of Health, UNICEF. District Profile Nuwaraeliya, Sri Lanka. Colombo: MOH and UNICEF, 2010.

6. Department of Census and Statistics, Ministry of Healthcare and Nutrition. Demographic and Health Survey 200607. Colombo: DCS and MOH, 2009.

7. Jayathissa R, Gunathilaka MM, Fernando DN. Aneamia among children aged 6-59 months and nutritional status of children and adults. Colombo: Ministry of Health, 2013.

8. Lwanga SK, Lemeshow S. Sample size determination in health studies; a practical manual. Geneva: World Health Organization, 1991. 
9. Family Health Bureau, Ministry of Health. Guidelines on Infant and Young child feeding. Colombo: Ministry of Health; 2007.

10. Birch LL, Fisher JO, Grimm-Thomas K, Markey CN, Sawyer R, Johnson SL. Confirmatory factor analysis of the Child Feeding Questionnaire: a measure of parental attitudes, beliefs and practices about child feeding and obesity proneness. Appetite. 2001;36(3):201-10.

11. Chika S, Shultz JA, Johnson SL, Branen LJ, Fletcher JW. Attitudes, concerns, and likelihood for action related to young children's overweight among early childhood program staff. Family \& community health. 2011;34(4):291-300.

12. Human Development Unit - South Asia Region. How likely and what will it take to reduce poverty, child mortality and malnutrition, and to increase school enrollment and completion? NewYork: The World Bank, 2005.
13. Passmore C, Dobbie AE, Parchman M, Tysinger J. Guidelines for constructing a survey. Family medicine. 2002;34(4):281-6.

14. Laferny PS. Early childhood professional development and classroom quality in preschool classrooms: Oklahoma State University; 2006.

15. Jayawickrama HS. Impact of responsive feeding on feeding behaviour of young children. Colombo: University of Colombo; 2006.

16. Child care education institute. Effective communication in child care Childcare education institute newsletter [Internet]. 2013 24/01/2014; 6(2). Available from: http://www.cceionline.edu/newsletters/ June_13_ext.html. 